do not observe, in an underpowered study, a pattern of mutual exclusivity between NFKBIA deletion and EGFR amplification when analyzing together grades II, III, and IV gliomas, nor do they find a relationship between survival and having a tumor that bears an NFKBIA deletion. Since the publication of our report, we have gone on to test these associations with the use of extended data from the Cancer Genome Atlas (TCGA) project. Using gene copy-number data generated by two independent TCGA Genome Characterization Centers on different genotyping platforms, we again observed a pattern of relative mutual exclusivity between deletion of NFKBIA and amplification of EGFR in glioblastomas $\left(\mathrm{P}=2 \times 10^{-3}\right.$ by Pearson's chisquare test; odds ratio for concomitant deletion and amplification, 0.46; 95\% confidence interval [CI], 0.29 to 0.74 ) (Fig. $1 \mathrm{~A}$ in the Supplementary Appendix, available with the full text of this letter at NEJM.org). We also again observed that patients with tumors with the NFKBIA deletion had poorer outcomes than did those who had glioblastomas with normal gene dosages of NFKBIA and EGFR (hazard ratio for death with the NFKBIA deletion, as compared with normal dosages of both NFKBIA and EGFR, 1.41; 95\% CI, 1.02 to 1.94; $\mathrm{P}=0.039$ by the Cox model), and had outcomes similar to those with tumors harboring EGFR amplification (hazard ratio for death with isolated NFKBIA deletion, as compared with isolated EGFR amplification, 0.93 ; 95\% CI, 0.68 to 1.29 ; $\mathrm{P}=0.68$ by the Cox model) (Fig. $1 \mathrm{~B}$ in the Supplementary Appendix). The estimated median survival times were 47 weeks for patients whose tumors harbored an isolated NFKBIA deletion, 53 weeks for those whose tumors had isolated EGFR amplification, and 67 weeks for those whose tumors had normal dosages of both NFKBIA and EGFR.

\section{Markus Bredel, M.D., Ph.D.}

University of Alabama at Birmingham Birmingham, AL

mbredel@uab.edu

Denise M. Scholtens, Ph.D.

Northwestern University

Chicago, IL

Since publication of their article, the authors report no further potential conflict of interest.

1. Kubicek GJ, Werner-Wasik M, Machtay M, et al. Phase I trial using proteasome inhibitor bortezomib and concurrent temozolomide and radiotherapy for central nervous system malignancies. Int J Radiat Oncol Biol Phys 2009;74:433-9.

2. Robe PA, Martin DH, Nguyen-Khac MT, et al. Early termination of ISRCTN45828668, a phase $1 / 2$ prospective, randomized study of sulfasalazine for the treatment of progressing malignant gliomas in adults. BMC Cancer 2009;9:372.

\title{
The Hemostatic System as a Modulator of Atherosclerosis
}

TO THE EDITOR: In their review article (May 5 issue), ${ }^{1}$ Borisoff et al. describe the role of hemostatic mechanisms as potential modulators of atherosclerotic plaque phenotype. Although they describe the role of thrombin as a critical mediator in the processes of coagulation, inflammation, and maintenance of vessel walls and even as an anticoagulant molecule, they provide no information regarding the contribution of the thrombin-activatable fibrinolysis inhibitor (TAFI) in these processes. TAFI is a procarboxypeptidase that on activation by thrombin or thrombin-thrombomodulin turns into a potent antifibrinolytic enzyme. TAFI acts as a molecular link between the processes of coagulation and fibrinolysis. Excessive TAFI levels can foster thrombosis by inducing a hypofibrinolytic state. In fact, plasma levels of TAFI are increased in patients with stroke and correlate with stroke severity in some studies..$^{2-4}$ In addition, TAFI significantly affected the effi- cacy of recombinant tissue plasminogen activator and vessel recanalization in patients undergoing thrombolysis after acute ischemic stroke. ${ }^{5}$ Because of the prominent role of thrombin in atherosclerosis, as stated by Borisoff et al., I believe that TAFI, a potent fibrinolytic inhibitor mediated by thrombin, should be included in discussions of the complex interplay between hemostasis and atherosclerosis.

José A. Páramo, M.D., Ph.D.

University Hospital of Navarra

Pamplona, Spain

japaramo@unav.es

No potential conflict of interest relevant to this letter was reported.

1. Borissoff JI, Spronk HMH, ten Cate H. The hemostatic system as modulator of atherosclerosis. N Engl J Med 2011;364:174660.

2. Montaner J, Ribó M, Monasterio J, Molina CA, Alvarez-Sabín J. Thrombin-activable fibrinolysis inhibitor levels in the acute phase of ischemic stroke. Stroke 2003;34:1038-40. 
3. Leebeek FW, Goor MP, Guimaraes AH, et al. High functional levels of thrombin-activatable fibrinolysis inhibitor are associated with an increased risk of first ischemic stroke. J Thromb Haemost 2005;3:2211-8.

4. de Bruijne EL, Gils A, Guimarães AH, et al. The role of thrombin activatable fibrinolysis inhibitor in arterial thrombosis at a young age: the ATTAC study. J Thromb Haemost 2009; 7:919-27.

5. Brouns R, Heylen E, Sheorajpanday R, et al. Carboxypeptidate U (TAFIa) decreases the efficacy of thrombolytic therapy in ischemic stroke patients. Clin Neurol Neurosurg 2009;111:16570 .

THE AUTHORS REPLY: We concur with Páramo that beyond modulating the ultimate clot size and lysis, the fibrinolytic cascade proteins (including $\mathrm{TAFI}^{1}$ ) may also contribute to the pathophysiology of cardiovascular disease. Nevertheless, the exact role of fibrinolysis in atherosclerosis remains highly controversial to date. Owing to space limitations, we restricted the scope of the review and did not cover this topic.

Hypofibrinolysis has been proposed as a determinant of cardiovascular disease in previous studies. $^{2}$ Aside from their recognized effects on fibrin clot lysis, fibrinolytic proteins, including the enzyme plasmin, should be recognized for their involvement in regulating many other actions, such as the plasmin-mediated accelerated inflammation and degradation of matrix proteins. Plasmin activates distinct matrix metalloproteinases (MMPs), such as MMP-3, 9, 12, and $13,{ }^{3}$ which have contributed to enhanced elastolysis and collagenolysis, tunica media destruction, and aneurysm formation in atherosclerotic mice models. ${ }^{4}$ Furthermore, despite the atheroprotective effect of plasminogen and urokinase-type plasminogen activator, the loss of plasminogen activator inhibitor 1 in atherosclerotic mice has been paradoxically linked to increased plaque growth and extracellular matrix deposition. ${ }^{5}$ Hence, the net effects of a fibrinolytic imbalance between plasminogen activators and their inhibitors on atherosclerosis progression remain poorly understood.

\section{Julian Ilcheff Borissoff, M.D. \\ Henri M.H. Spronk, Ph.D. \\ Hugo ten Cate, M.D., Ph.D.}

Maastricht University Medical Center

Maastricht, the Netherlands

h.tencate@maastrichtuniversity.nl

Since publication of their article, the authors report no further potential conflict of interest.

1. Bouma BN, Meijers JC. New insights into factors affecting clot stability: a role for thrombin activatable fibrinolysis inhibitor (TAFI; plasma procarboxypeptidase B, plasma procarboxypeptidase U, procarboxypeptidase R). Semin Hematol 2004;41: Suppl 1:13-9.

2. Meltzer ME, Doggen CJ, de Groot PG, Rosendaal FR, Lisman T. The impact of the fibrinolytic system on the risk of venous and arterial thrombosis. Semin Thromb Hemost 2009;35:46877.

3. Lijnen HR. Plasmin and matrix metalloproteinases in vascular remodeling. Thromb Haemost 2001;86:324-33.

4. Carmeliet P, Moons L, Lijnen R, et al. Urokinase-generated plasmin activates matrix metalloproteinases during aneurysm formation. Nat Genet 1997;17:439-44.

5. Luttun A, Lupu F, Storkebaum E, et al. Lack of plasminogen activator inhibitor-1 promotes growth and abnormal matrix remodeling of advanced atherosclerotic plaques in apolipoprotein E-deficient mice. Arterioscler Thromb Vasc Biol 2002;22:499505.

\section{In Vivo Biomechanical Measurements of a Football Player's C6 Spine Fracture}

TO THE EDITOR: During an investigation of concussion in American football players, we captured in vivo biomechanical data on a cervical spine fracture as it occurred in a male athlete (age, 18 years; height, $189.0 \mathrm{~cm}$; weight, $79.4 \mathrm{~kg}$ ) who was performing a head-down tackling maneuver. The cornerback's helmet was equipped with the Head Impact Telemetry System (Simbex), a six-accelerometer array that measures the location and magnitude of an impact. The impact magnitude was quantified by measuring peak linear and rotational acceleration of the head with the use of the Gadd Severity Index (GSI) and
Head Injury Criteria (HIC)., ${ }^{1,2}$ The GSI and HIC are mathematically weighted measures of head acceleration and the duration of impact, with higher scores representing increased likelihood of injury.

After being transported to the emergency department, the athlete reported having pain in the head, neck, and lower back (severity between 3 and 5 on a scale of 0 through 10 , with 0 indicating no pain and 10 indicating most severe pain) and losing consciousness for less than 10 seconds at the time of injury. A computed tomographic (CT) scan of the brain was normal, but 